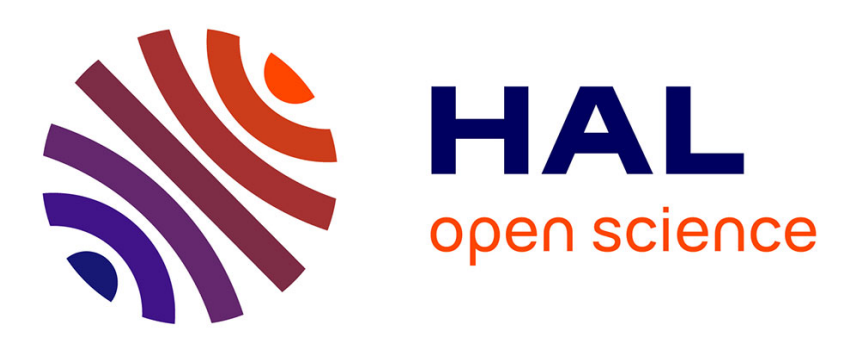

\title{
Contributions to the entropy change in melt-spun LaFe11.6Si1.4
}

K Morrison, J Lyubina, Jd Moore, Ad Caplin, Kg Sandeman, O Gutfleisch, Lf Cohen

\section{- To cite this version:}

K Morrison, J Lyubina, Jd Moore, Ad Caplin, Kg Sandeman, et al.. Contributions to the entropy change in melt-spun LaFe11.6Si1.4. Journal of Physics D: Applied Physics, 2010, 43 (13), pp.132001. 10.1088/0022-3727/43/13/132001 . hal-00569565

\section{HAL Id: hal-00569565 https://hal.science/hal-00569565}

Submitted on 25 Feb 2011

HAL is a multi-disciplinary open access archive for the deposit and dissemination of scientific research documents, whether they are published or not. The documents may come from teaching and research institutions in France or abroad, or from public or private research centers.
L'archive ouverte pluridisciplinaire HAL, est destinée au dépôt et à la diffusion de documents scientifiques de niveau recherche, publiés ou non, émanant des établissements d'enseignement et de recherche français ou étrangers, des laboratoires publics ou privés. 


\title{
Contributions to the Entropy Change in Melt-spun $\mathrm{LaFe}_{11.6} \mathrm{Si}_{1.4}$
}

\author{
K Morrison ${ }^{1}, \mathrm{~J}_{\text {Lyubina }}{ }^{2}, \mathrm{JD}_{\text {Moore }}{ }^{1}, \mathrm{AD}$ Caplin $^{1}, \mathrm{KG}$ Sandeman $^{1}, \mathrm{O}_{\text {Gutfleisch }}{ }^{2} \&$ LF Cohen $^{1}$ \\ ${ }^{I}$ The Blackett Laboratory, Imperial College, London SW7 2BZ, UK \\ ${ }^{2}$ IFW Dresden, PO Box 260016, D-01171 Dresden, Germany
}

\begin{abstract}
Here we study the calorimetric and magnetic behaviour of melt-spun $\mathrm{LaFe}_{11.6} \mathrm{Si}_{1.4}$, a potential magnetic refrigerant material system that exhibits the rare combination of a large entropy change and low thermal and magnetic field hysteresis. We are able to separate the calorimetric contribution from latent heat and changes in equilibrium heat capacity explicitly by using two separate calorimetric probes. The heat capacity of this sample exhibits significant changes of the order of $500-1000 \mathrm{JK}^{-1} \mathrm{~kg}^{-1}$ in response to magnetic field that results in large changes in entropy. The different contributions to entropy change from latent heat and heat capacity are shown to evolve as the material is field driven through its itinerant metamagnetic transition. We demonstrate explicitly that in the melt spun sample studied here, the majority of the total entropy change comes from the equilibrium change of heat capacity.
\end{abstract}

PACs: $75.30 . S g$ 


\section{Introduction}

Systems that show a large magnetocaloric effect around room temperature are of increasing interest due to their possible application in magnetic cooling at room temperature. A significant boost to the field came about when it was realized that materials exist that provide giant entropy changes when driven in magnetic field due to the first order nature of the magnetic phase transition. ${ }^{1,2}$ Nevertheless the downside of first order behaviour is the large magnetic and thermal hysteresis $\left(\Delta \mathrm{H}_{\mathrm{M}} \& \Delta \mathrm{H}_{\mathrm{th}}\right)$, and associated loss in efficiency in the cooling cycle when the material is taken around a complete magnetic field or temperature hysteresis cycle. The itinerant metamagnetic $\mathrm{La}\left(\mathrm{Fe}_{\mathrm{x}} \mathrm{Si}_{1-\mathrm{x}}\right)_{13}$ is one of the most interesting systems ${ }^{3,4,5}$ offering large $\Delta \mathrm{S}$ of up to $120 \mathrm{kJm}^{-3} \mathrm{~K}^{-1}$ in a field change of $0-2 \mathrm{~T},{ }^{3}$ coupled with an unusually low $\Delta \mathrm{H}_{\mathrm{M}}$. It has also been shown that preparation of the material by the melt-spinning technique acts to reduce extrinsic contributions to $\Delta \mathrm{H}_{\mathrm{M}}$ and $\Delta \mathrm{H}_{\mathrm{th}}{ }^{4}$ Nevertheless understanding the contributions to the entropy change, $\Delta \mathrm{S}$, and associated hysteresis is one of the most challenging problems in this field today. ${ }^{6}$

A considerable effort has been dedicated to studying the entropy change in terms of lattice, electronic and magnetic contributions, although convergence of views is not yet complete. From a localized moment model, ${ }^{7}$ it has been suggested that in $\mathrm{La}\left(\mathrm{Fe}_{x} \mathrm{Si}_{1-\mathrm{x}}\right)_{13}$, the lattice $\Delta \mathrm{S}$ adds in opposition to the magnetic $\Delta \mathrm{S}$, in part because $\mathrm{La}\left(\mathrm{Fe}_{\mathrm{x}} \mathrm{Si}_{1-\mathrm{x}}\right)_{13}$ belongs to the Invar family of materials that show a lattice contraction when heated. Theoretical work on the band structure of $\mathrm{La}(\mathrm{Fe}, \mathrm{Si})_{13}$ suggests that the low intrinsic hysteresis observed for this system is dependent on the presence of multiple shallow minima in the free energy ${ }^{8}$ as a function of the magnetic moment, thereby associating hysteresis with the energy barriers that separates the different magnetic phases of the material. Experimental work on hydrogenated samples under pressure ${ }^{9}$ offers strong support for this model. The significant volume of work from Fujita, Fukamichi and co-workers ${ }^{10}$ provides insight into the magnetic behaviour in terms of spin fluctuation theory and concludes 
that the latent heat in the system is directly related to the change in magnetic state. Indeed the system shows a large change of magnetization. ${ }^{1}$ Clearly a direct measure of the separate contributions to entropy change would further our understanding of this important system.

Here we study the calorimetric and magnetic behaviour of melt-spun $\mathrm{LaFe}_{11.6} \mathrm{Si}_{1.4}$, and by using two different calorimetric probes we separate latent heat and equilibrium heat capacity changes. A similar methodology has been set out by Marcos et al. ${ }^{11,12}$ We find that although the total $\Delta \mathrm{S}$ in $\mathrm{LaFe}_{11.6} \mathrm{Si}_{1.4}$ is comparable with other forms of the material such as arc melted bulk material, ${ }^{13}$ unlike this form and first order metamagnetic antiferromagnets such as $\mathrm{CoMnSi},{ }^{14}$ it is the changes in the equilibrium heat capacity that provides the major contribution to the total $\Delta \mathrm{S}$ in $\mathrm{LaFe}_{11.6} \mathrm{Si}_{1.4}$ in its melt spun form.

\section{Experimental}

A $\mathrm{LaFe}_{11.6} \mathrm{Si}_{1.4}$ alloy was prepared by arc melting in Ar atmosphere and subsequent melt spinning. The surface speed of the rotating copper wheel was $30 \mathrm{~m} / \mathrm{s}$. The as-spun ribbons were annealed at $1050{ }^{\circ} \mathrm{C}$ for $2 \mathrm{~h}$ followed by quenching in water. According to Rietveld refinement of X-ray data the ribbons contained the $\mathrm{La}(\mathrm{Fe}, \mathrm{Si})_{13}$ phase and a minor amount of $\alpha-\mathrm{Fe}$ (about $5 \mathrm{wt} . \%$ ). The Curie temperature of the prepared ribbons was estimated from the Arrott plots to be $185 \mathrm{~K}$.

Magnetization and calorimetry measurements were carried out in fields up to 8T and temperatures ranging from $80-295 \mathrm{~K}$. Latent heat and ac calorimetry measurements were performed on approximately 100x50x30 $\mu \mathrm{m}$ sized fragments taken from a melt-spun ribbon.

The ac heat capacity measurement ${ }^{15}$ is operated in helium exchange gas, using an ac temperature ripple of (in this case) $0.07 \mathrm{~K}$ at a frequency, $\mathrm{f}=5 \mathrm{~Hz}$, generated by resistive heater strips. The 
change in sample temperature is measured using a phase sensitive lock in technique (at $2 \mathrm{f}$, with a 1s time constant) to detect the voltage generated across the thermopile. Latent heat can only be captured if the 'temperature ripple' is large compared to the thermal hysteresis of the sample which is not the case here as the thermal hysteresis is approximately $0.8 \mathrm{~K}$ at $\mathrm{T}_{\mathrm{c}}$. A thorough discourse on why latent heat cannot be fully captured using the ac calorimetric technique has also been discussed elsewhere. ${ }^{16}$ The latent heat probe,${ }^{17}$ in contrast is set up in vacuum. We only use the probe at fixed bath temperature in swept magnetic field mode. There are two important time scales; the system relaxation time to the bath temperature which is of the order of $1 \mathrm{~s}$ and the magnetic field sweep rate which is $8.3 \mathrm{mT} / \mathrm{s}$. This probe captures the latent heat component fully. Therefore we use the ac calorimetry probe to determine the equilibrium change in heat capacity at zero and fixed field and the latent heat probe to determine the latent heat component.

To calculate the entropy change of the fragment due to latent heat $\left(\Delta \mathrm{S}_{\mathrm{LH}}\right)$ or the change in heat capacity $\left(\Delta \mathrm{S}_{\mathrm{HC}}\right)$, equations (1) and (2) are used,

$$
\begin{aligned}
& \Delta S_{L H}=-\Delta Q_{L} / T \\
& \Delta S_{H C}(T>185 K)=\int_{T}^{T 1}((C(H, T)-C(0, T)) / T) d T
\end{aligned}
$$

where $\Delta \mathrm{Q}_{\mathrm{L}}$ is the heat output due to latent heat at temperature $\mathrm{T}$ (calibrated using a reference pulse as described in ref 17 ), and $\mathrm{C}(\mathrm{H}, \mathrm{T})$ is the heat capacity in magnetic field $\mathrm{H}$ (chosen to be $4 \mathrm{~T}$ ) at $\mathrm{T}$. The reference temperature, T1, used in the integral of Eq. (2) was chosen as 240K. A finite zero field latent heat term exists at $T_{c}$ in this system, which means that when integrating from $240 \mathrm{~K}$ to below $\mathrm{T}_{\mathrm{c}}(=185 \mathrm{~K})$ this needs to be added to Eq. (2) to fully account for a change of state from PM to FM.

$$
\Delta S_{H C}(T<185 K)=\int_{T}^{T 1}((C(H, T)-C(0, T)) / T) d T+\left.\Delta S_{L H}(F M \rightarrow P M)\right|_{T_{c}}
$$


Further details of the experimental techniques used are given elsewhere. ${ }^{14,15,17}$ The total, $\Delta \mathrm{S}_{\text {total }}=\Delta \mathrm{S}_{\mathrm{HC}}+\Delta \mathrm{S}_{\mathrm{LH}}$, can be compared to the entropy calculated from bulk samples, ${ }^{14,18}$ which is calculated here by numerical integration of isothermal M-H loops using the Maxwell relation. ${ }^{6}$

It is known that in this system there is coincident isostructural volume expansion during the transition from the paramagnetic (PM) to the ferromagnetic (FM) state of the order of $1.5 \% .^{19}$ Here we use the heater resistance, $R_{h}$, embedded in the silicon nitride membrane, as a measure of the expansion in one dimension. ${ }^{15}$ The change of $\mathrm{R}_{\mathrm{h}}$ due to lattice expansion of the sample is not calibrated precisely, but it provides a useful and reproducible guide to volume changes alongside heat capacity measurements. Similar results were obtained from several samples when normalized by mass.

\section{Results and Discussion}

Figure 1 shows the $M-H$ loop of a melt-spun ribbon with dimensions of $2 \mathrm{~mm}$ x $1 \mathrm{~mm} \times 0.03 \mathrm{~mm}$ and the magnetic field applied perpendicularly to the plane of the sample at a sweep rate of $0.5 \mathrm{~T} / \mathrm{min}$. We also look at the properties of thirty $\sim 100 \mu \mathrm{m}^{3}$ sized melt-spun fragments taken from the sample to see how fragmentation affects the magnetization properties. The $\Delta \mathrm{H}_{\mathrm{M}}$ in the meltspun samples is already small but the data shows that fragmentation reduces this even further. Although the onset field in bulk and fragment is similar, a larger applied field is required to complete the transition in the fragments. In this sense the transition is broadened in the fragment. Note that the saturation magnetization in the collection of fragments is slightly lower, and from figure 1(b) it can be seen that the phase line is suppressed by approximately $2 \mathrm{~K}$. 

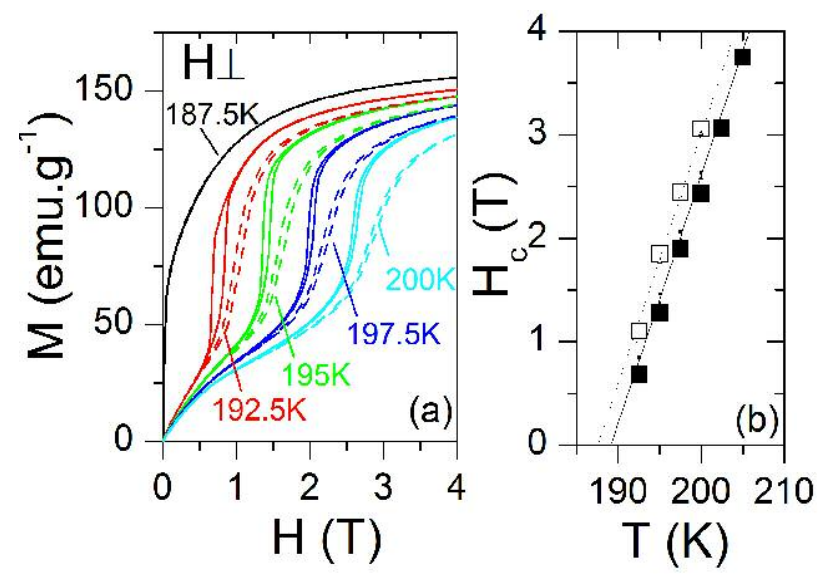

Figure 1 - a) $M-H$ loop of whole (solid curve) and fragmented ribbons (dashed curve) when the field is aligned perpendicular to the sample plane at $192.5 \mathrm{~K}, 195 \mathrm{~K}, 197.5 \mathrm{~K}$ and $200 \mathrm{~K}$. b) H-T phase diagram from this data (whole ribbon $\square$, fragments $\square$ ), where $H_{c}$ is determined as the point at which $\mathrm{M}$ is $50 \%$ of its saturation value. The phase line of the fragments cuts the $\mathrm{x}$ axis at $187.5 \mathrm{~K}$ and that of the bulk at $189.5 \mathrm{~K}$, suggesting that fragmentation results in a lower $\mathrm{T}_{\mathrm{c}}$.

Figure 2 shows the heat capacity and latent heat measurements explicitly. It is important to note that the heat capacity peak feature shown in figure 2(a) is not associated with latent heat. It does not mirror the change of sign on reversing the magnetic field direction (indicated by solid and open symbols) that is seen for the latent heat spikes shown in figure 2(b), and the temperature evolution of the magnitude of the peak in heat capacity (which first increases as the temperature is increased away from $T_{c}$ ) and the latent heat spikes (which decrease rather linearly with increasing temperature away from $\mathrm{T}_{\mathrm{c}}$ ) are also quite different. The combination of these observations, as well as arguments given elsewhere, ${ }^{16}$ support the view that ac calorimetry does not capture latent heat. We therefore believe that the features captured with the ac heat capacity probe are related to spin fluctuations as discussed elsewhere ${ }^{13}$ and they are clearly enhanced and sharpened by the first order nature of the transition. Note that the data used to calculate $\Delta \mathrm{S}_{\mathrm{HC}}$ is taken from the curves at 0T and $4 \mathrm{~T}$ as indicated in the schematic in the inset to figure 2(a). 

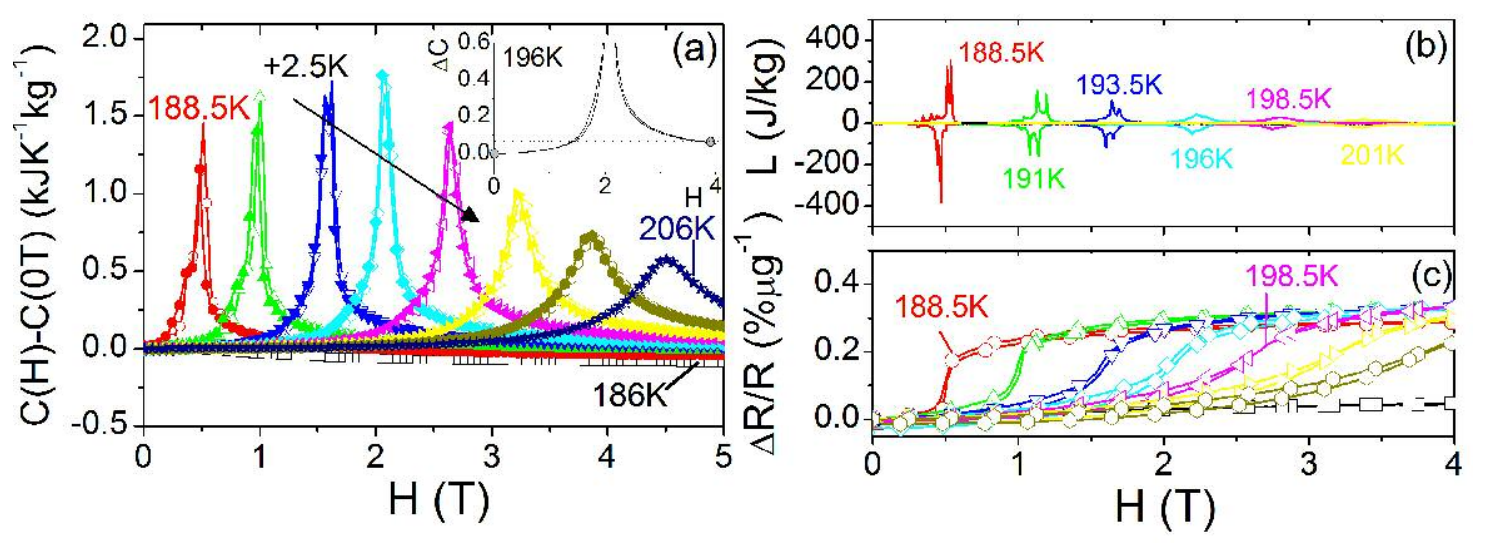

Figure 2 - Raw data taken from micro-calorimetry. a) Change in heat capacity for increasing field (open symbols) and decreasing field (closed symbols), where for $\mathrm{T}=188.5 \mathrm{~K}$ to $193.5 \mathrm{~K}, \mathrm{C}(0 \mathrm{~T})$ varied from 0.49 to $0.45 \pm 0.05 \mathrm{kJK}^{-1} \mathrm{~kg}^{-1}$. The inset shows a schematic showing how $\Delta \mathrm{C}(0 \mathrm{~T}-4 \mathrm{~T})$ is extracted for use in Eq. (2). b) Latent heat for both field directions. c) Magnetostriction, $\Delta R / R$ [15] as a function of increasing field at temperature intervals of $2.5 \mathrm{~K}$. Note that as temperature increases the start and end fields in the volume expansion process diverge.

The magnetic field driven latent heat term shown in figure 2(b), is large and well-defined close to $\mathrm{T}_{\mathrm{c}}$ and then drops rather linearly towards zero (in increasing temperature). Again this is entirely consistent with spin fluctuation theory, as discussed in more depth in Ref. [10]. (Note that because multiple peaks in latent heat are observed, the total $\Delta \mathrm{Q}_{\mathrm{L}}$ will be proportional to the integral of the signal shown in figure 2(b)). Above $201 \mathrm{~K}$ the heat capacity shows large broad changes that are not mirrored in the latent heat but are reflected in the qualitative measure of magnetostriction, $\Delta R / R$, which is shown in figure 2(c). Interestingly $\Delta R / R$ changes from a sharp step like feature to a more continuous change as the temperature is increased away from $T_{c}$, which supports the suggestion that the move towards continuous behaviour observed here is due to thermal effects rather than a weakening of the spin-lattice coupling. As the temperature is increased the energy barrier between the equilibrium magnetic phases decreases, eventually tending to zero as the latent heat term tends to zero. 
Figure 3 shows the contributions to $\Delta \mathrm{S}$ determined calorimetrically, (from the two separate components measured in the heat capacity and latent heat probes), in two single fragments compared to $\Delta \mathrm{S}$ obtained from the bulk (ribbon) magnetization measurements. The $\Delta \mathrm{S}_{\text {total }}$ $\left(=\Delta \mathrm{S}_{\mathrm{HC}}+\Delta \mathrm{S}_{\mathrm{LH}}\right)$ from two separate single fragments agrees well with $\Delta \mathrm{S}_{\text {Maxwell }}$, and from this we can infer that the fragmentation process has not significantly changed the fundamental properties of the sample and also that our method of separating the contributions to the entropy change is robust i.e. the total calorimetric and the total magnetization contributions are comparable. The key observation is that in these melt spun materials the majority of $\Delta \mathrm{S}(4 \mathrm{~T})$ comes from changes in the equilibrium heat capacity $\Delta \mathrm{S}_{\mathrm{HC}}$ at $0 \mathrm{~T}$ and $4 \mathrm{~T}$, and that the $\Delta \mathrm{S}_{\mathrm{HC}}$ component is almost temperature independent. The magnitude of $\Delta \mathrm{S}_{\mathrm{HC}}$ drops to zero at a temperature where the critical field of the phase transition exceeds the maximum applied field which at $4 \mathrm{~T}$ corresponds to $\mathrm{T}>206 \mathrm{~K}$ (see the phase line in figure 1(b)). Note that the bulk and fragment phase lines are shifted slightly. This shift is not manifest in figure 3 because the data points have been averaged over a $5 \mathrm{~K}$ temperature span as part of the numerical integration process. It is interesting to note that the balance of these contributions to entropy change may be different in the arc melted material compared to other forms of this compound, ${ }^{13}$ suggesting that morphology and processing may affect the relative contributions of spin, electronic and lattice terms, even though the total entropy change remains equivalent.

The inset in figure 3 shows $\Delta \mathrm{H}_{\mathrm{M}}$ in the melt-spun sample as a function of temperature. The hysteresis is largest where the latent heat contribution is greatest, that is, close to $T_{c}$. As the temperature is increased $\Delta \mathrm{H}_{\mathrm{M}}$ decreases, tending towards zero where the latent heat term disappears. This observation supports the premise that at this temperature the energy barrier 
between phases is overcome by thermal fluctuations ${ }^{10}$ and consequently the material shows no hysteresis. Above this temperature the transition is effectively second order

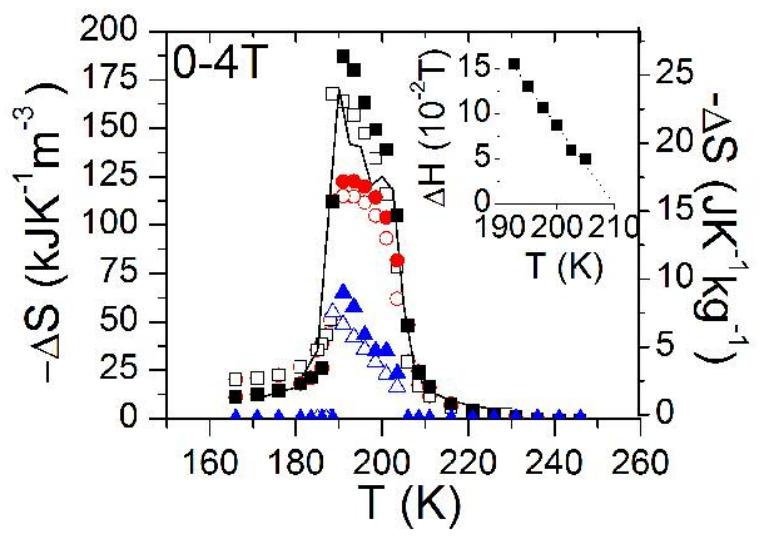

Figure 3 - Comparison of the $\Delta \mathrm{S}$ contributions calculated from heat capacity $(\mathrm{O})$ and latent heat $(\Delta)$ measurements of a $\sim 100$ micron melt-spun fragment. $\Delta \mathrm{S}_{\text {Total }}(\square)$ is the sum of the two contributions and is comparable to $\Delta \mathrm{S}_{\text {Maxwell }}$ for a $2 \mathrm{x} 1 \mathrm{~mm}$ ribbon (solid line). Open and solid symbols indicate the results for two separate fragments, A and B respectively.

The adiabatic entropy change, $\Delta \mathrm{T}_{\mathrm{ad}}$ can be determined from heat capacity and magnetisation data by using equation (4). ${ }^{20}$ Often however, if the field-dependent heat capacity at a given temperature is not known then $\Delta \mathrm{T}_{\mathrm{ad}}$ will be estimated by assuming that the heat capacity is independant of field as shown by equation (5). As stated elsewhere, ${ }^{20}$ large changes in heat capacity in response to applied magnetic field will result in additional errors to the use of equation (5).

$$
\begin{aligned}
& \Delta T_{a d}(T)_{\Delta H}=-\int_{H_{I}}^{H_{F}}\left(\frac{T}{C(T, H)}\right)_{H}\left(\frac{\partial M(T, H)}{\partial T}\right)_{H} d H \\
& \Delta T_{a d} \approx \frac{T}{C(T)_{H}} \Delta S_{M}(T)_{\Delta H}
\end{aligned}
$$


In the case of the $\mathrm{LaFe}_{11.6} \mathrm{Si}_{1.4}$ compound shown here, we have demonstrated explicitly that significant changes in heat capacity (of the order of 100\%) occur about the phase transition. Fujita and Fukamichi ${ }^{13}$ infer by indirect measurement that there is an enhancement of heat capacity due to the amplitude of the thermal spin fluctuations in the paramagnetic phase. Their conclusions are supported by their observation of a factor of two enhancement of the paramagnetic susceptibility. The explicit field dependence of the heat capacity enhancement associated with spin fluctuations at a first order itinerant electron transition has not been previously reported (as far as we are aware), in part because of the difficulty of separating out the latent heat contribution. Here we have overcome that difficulty by measuring the heat capacity and latent heat contributions separately, and consistent with previous work ${ }^{13}$ we can make an explicit association between the heat capacity peak feature and the significant spin fluctuations in these materials. The feature is clearly enhanced and sharpened by the first order nature of the transition. The impact of these large changes is to lower the maximum achievable $\Delta \mathrm{T}_{\text {ad }}$ as was observed by a comparison of indirect and direct measurements of $\Delta \mathrm{T}_{\mathrm{ad}}$ by Fujieada et al. ${ }^{21}$ If the large enhancement of the heat capacity observed here is a general feature of itinerant electron metamagnetic systems, it is expected that $\Delta \mathrm{T}_{\text {ad }}$ will always be limited in some degree by $\mathrm{C}(\mathrm{H}, \mathrm{T})$ whether the transition is of first or second order.

\section{Conclusion}

Our independent probes allow us to observe that in melt-spun $\mathrm{LaFe}_{11.6} \mathrm{Si}_{1.4}$ ribbons the change in the equilibrium heat capacity provides the dominant contribution to $\Delta \mathrm{S}_{\text {total }}$, even close to the zero field $\mathrm{T}_{\mathrm{c}}$ of the system We show that fragmentation of the sample lowers the effective hysteresis, which is an additional important observation for application of the material, although the process is neither controlled here nor fully understood and will be the subject of further study. 


\section{Acknowledgments}

This work was supported by EPSRC Platform grant EP/E016243/1 - A Platform to Develop and Utilize Characterization Tools for Functional Magnetic Materials, European Commission Grant No. FP7 CP-FP 214864-2 Solid State Energy Efficient Cooling (SSEEC) and by the Deutsche Forschungsgemeinschaft (DFG), contract No. RI 932/4-1.

\section{References}

\footnotetext{
${ }^{1}$ Pecharsky VK \& Gschneidner, Jr., KA 1997 Phys. Rev. Lett. 78, 004494

${ }^{2}$ Wada H, Morikawa T, Taniguchi K, Shibata T, Yamada Y \& Akishige Y, 2003 Physica B 328, 114-116

${ }^{3}$ Lyubina J, Gutfleisch O, Ku'zmin MD \& Richter M, 2009 J. Magn. Magn. Mater. 321, 3571-3577

${ }^{4}$ Gutfleisch O, Yan A \& Müller KH, 2005 J. Appl. Phys. 97, 10M305

${ }^{5}$ Fujita A, Fujieda S, Hasegawa Y \& Fukamichi K, 2003 Phys. Rev. B 67, 104416

${ }^{6}$ Tishin AM \& Spichkin YI, 2003 The Magnetocaloric Effect and its Applications, Institute of Physics,

Bristol

${ }^{7}$ Jia L, Liu GJ, Sun JR, Zhang HW, Hu FX, Dong C, Rao GH, \& Shen BG, 2006 J. Appl. Phys. 100, 123904

${ }^{8}$ Ku'zmin MD \& Richter M, 2007 Phys. Rev. B 76, 092401

${ }^{9}$ Lyubina J, Nenkov K, Schultz L \& Gutfleisch O, 2008 Phys. Rev. Lett. 101, 177203

${ }^{10}$ Fujita A, Fujieda S \& Fukamichi,K 2004 J. Magn. Magn. Mater. 272 e629

11 Marcos J, Casanova F, Batlle X, Labarta A \& Planes A, 2003 Rev. Sci. Instrum., 744768

${ }^{12}$ Casanova F, Batlle X, Labarta A, Marcos J, Mañosa L, \& Planes A, 2002 Phys. Rev. B 66, 212402

${ }^{13}$ Fujita A \& Fukamichi K, 2006 J. All. \& Comp. 408-412 62-65

${ }^{14}$ Morrison K,Miyoshi Y, Moore JD, Barcza A, Sandeman KG, Caplin AD \& Cohen LF, 2008 Phys. Rev.

$B$ 78, 134418

${ }^{15}$ Minakov AA, Roy SB, Bugoslavsky YV \& Cohen LF, 2005 Rev. Sci. Instr. 76, 043906

${ }^{16}$ Saruyama Y, 1992 J. Therm. Anal. 38 1827-1833

${ }^{17}$ Miyoshi Y, Morrison K, Moore JD, Caplin AD \& Cohen LF, 2008 Rev. Sci. Instr. 79074901
} 
${ }^{18}$ Morrison K, Moore JD, Sandeman KG, Caplin AD \& Cohen LF, 2009 Phys. Rev. B 79, 134408

${ }^{19}$ Fujita A, Akamatsu Y \& Fukamichi K, 1999 J. Appl. Phys. 85, 4756

${ }^{20}$ Pecharsky VK \& Gschneidner Jr KA, 1999 J. Appl. Phys. 86, 565-575

${ }^{21}$ Fujieda S, Hasegawa Y, Fujita A \& Fukamichi K, 2004 J. Magn. \& Magn. Mater. 272-276, 2365-2366 


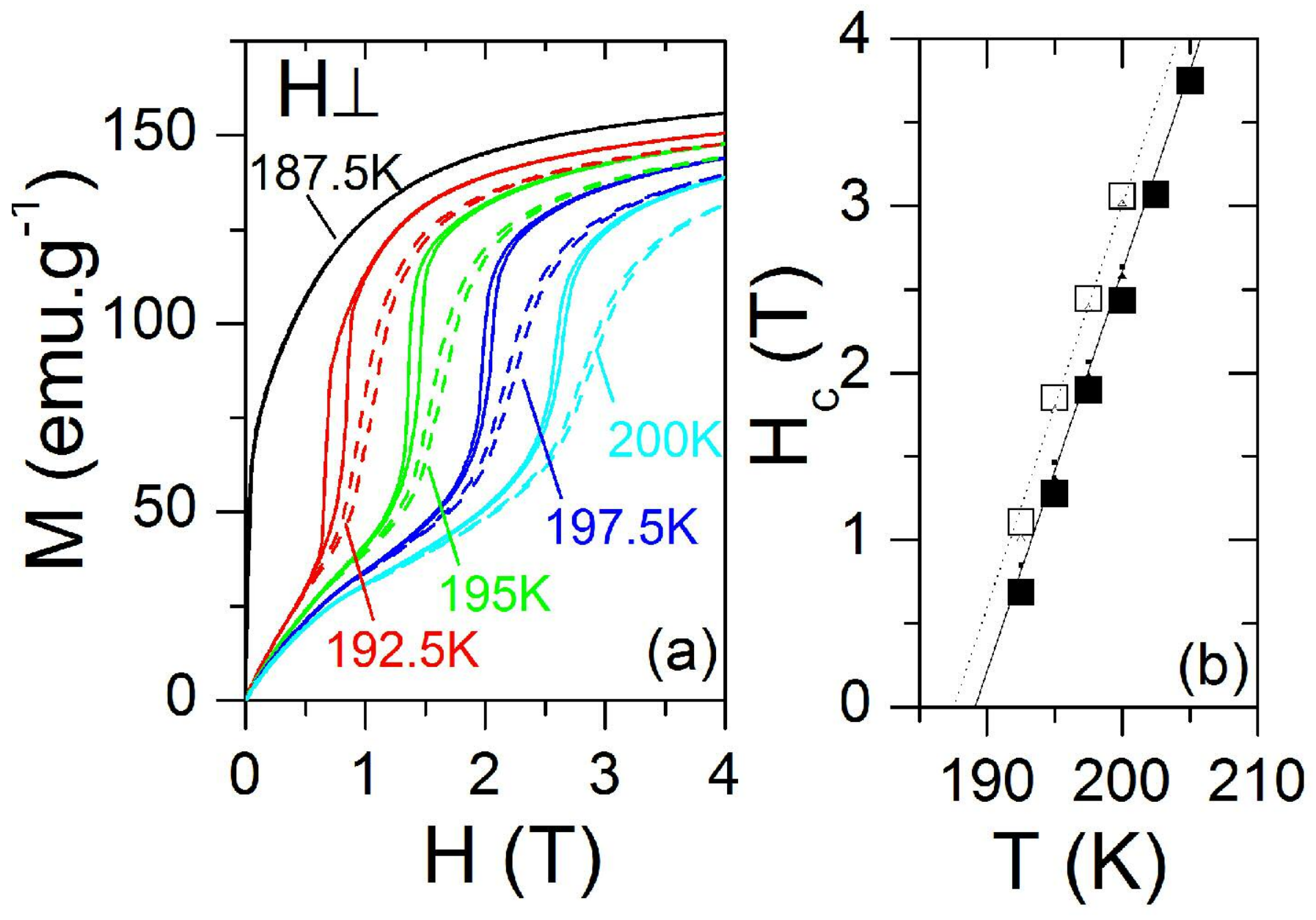

Figure 1 (fig1.JPG) 


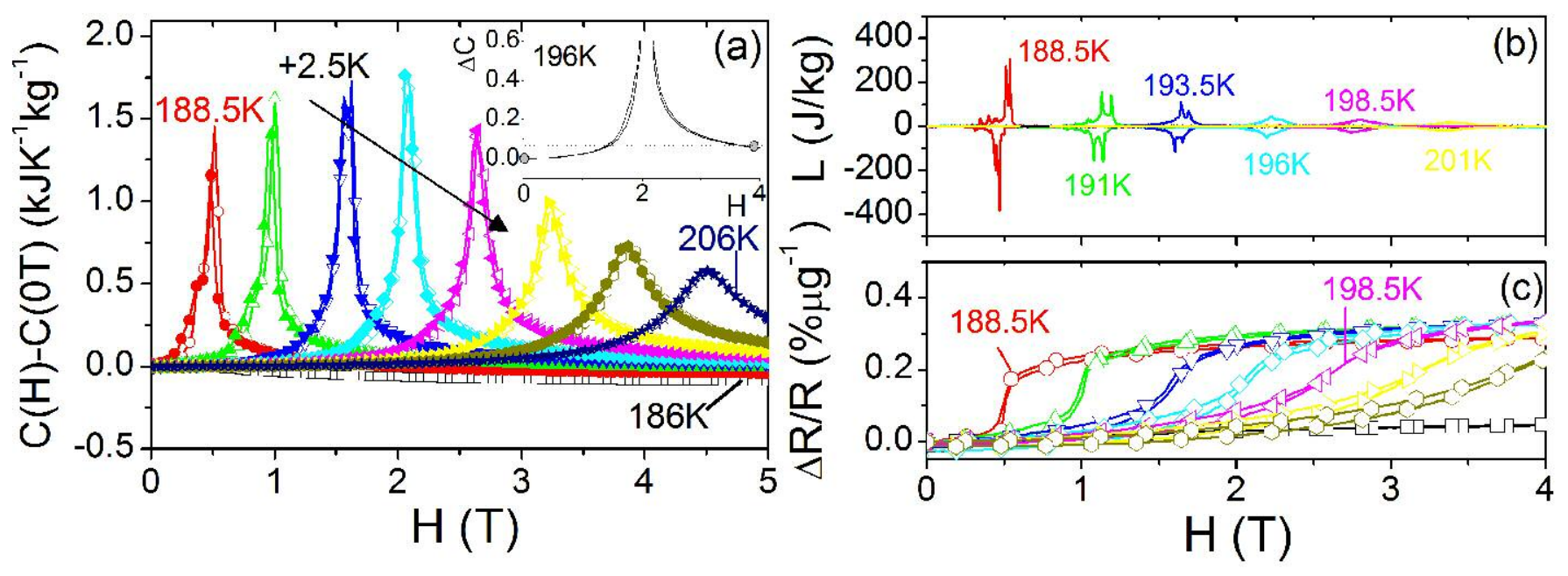

Figure 2 (fig 2.JPG) 


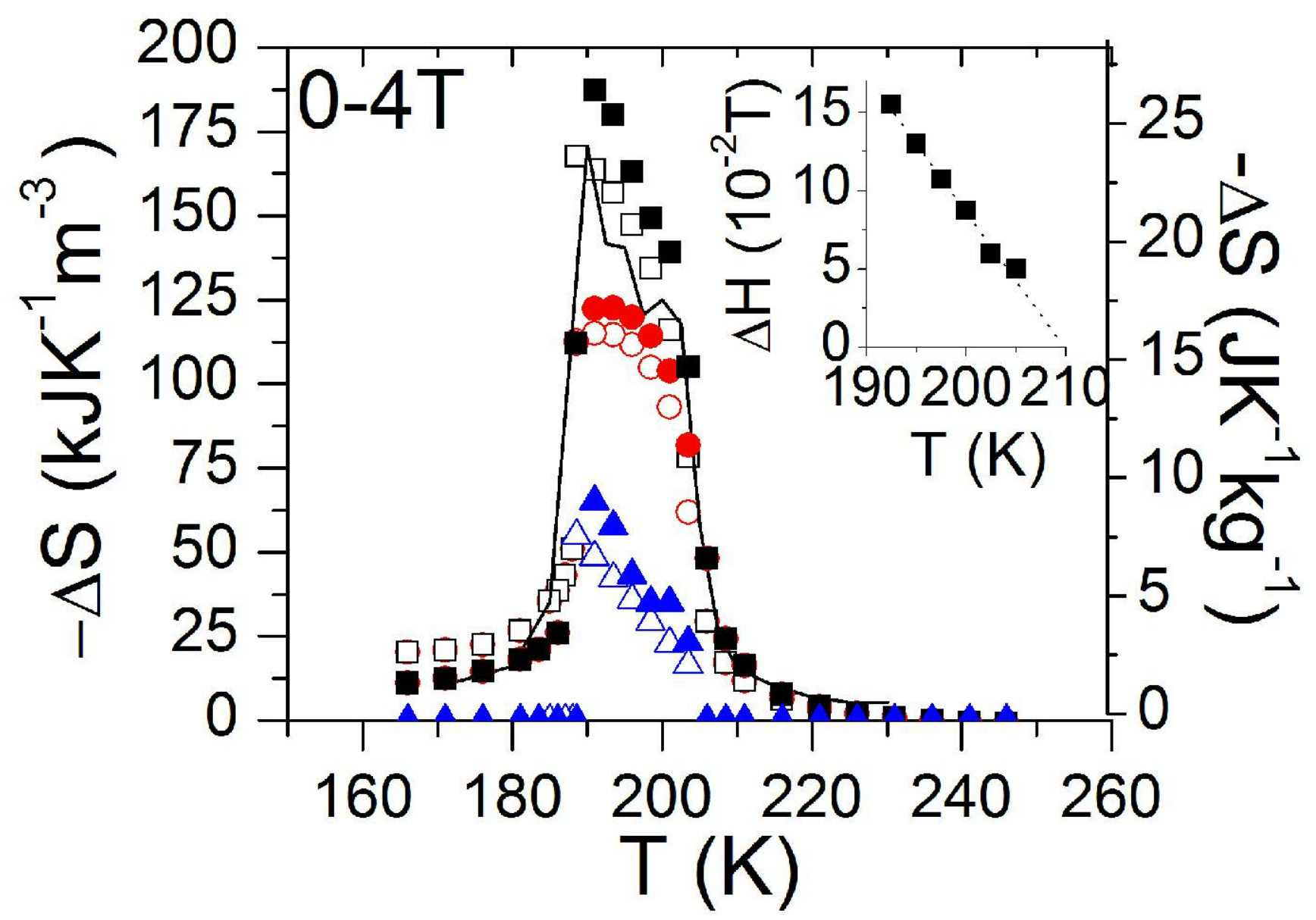

Figure 3 (fig 3.JPG) 